\title{
SOROPREVALÊNCIA DE ANTICORPOS ANTI-Neospora caninum E ANTI-Leptospira interrogans EM DUAS PROPRIEDADES DE VACAS LEITEIRAS COM RELATOS DE PREJUÍZOS REPRODUTIVOS NO MUNICÍPIO DE GOIANDIRA, GOIÁS
}

\author{
Rafael Quirino Moreira, ${ }^{1}$ Dagmar Diniz Cabral, ${ }^{2}$ Anna Monteiro Correia Lima ${ }^{3}$ E \\ Paulo Roberto Oliveira ${ }^{4}$
}

1. Mestrando do Programa de Pós-Graduação em Ciências Veterinárias da Faculdade de Medicina Veterinária / UFU. E-mail: beletim@yahoo.com.br

2. Mestre e professora de Parasitologia Veterinária do Instituto de Ciências Biomédicas da Universidade Federal de Uberlândia

3. Doutora, professora de Doenças Bacterianas da Faculdade de Medicina Veterinária da Universidade Federal de Uberlândia

4. Doutor, professor de Epidemiologia Veterinária da Faculdade de Medicina Veterinária da Universidade Federal de Uberlândia.

\section{RESUMO}

O objetivo deste estudo foi determinar a soroprevalência de anticorpos anti-Neospora caninum e anti-Leptospira interrogans em vacas leiteiras do município de Goiandira, Goiás, Brasil. Testaram-se amostras de soro sanguíneo de 53 bovinos de dois rebanhos para detecção de anticorpos anti- $N$. caninum e anti-L. interrogans, utilizando as técnicas de Reação de Imunufluorescência Indireta (RIFI) e Reação de Soroaglutinação Microscópica (MAT), respectivamente. Consideraram-se positivos os soros reagentes a uma diluição de 1:50 para N. caninum e 1:100 para L. interrogans. Encontraram-se 35,9\% (14 vacas) dos animais positivos para $N$. caninum na Fazenda 1, e 64,3\% (9 vacas) dos animais da Fazenda 2. Para leptospirose, foram sororreagentes $87,2 \%$ (34 vacas) dos animais da Fazenda 1 e 64,3\% (9 vacas) dos animais da Fazenda 2. Os sorovares encontrados foram: wolffi $(21,74 \%)$, hardjo $(18,11 \%)$; bratislava (14,49\%); australis (12,32\%); tarassovi $(12,32 \%)$; icterohaemorrhagiae $(7,25 \%)$; sentot $(5,80 \%)$; grippotyphosa $(5,07 \%)$; patoc $(2,17 \%)$; cynoptero $(0,72 \%)$. De acordo com esses resultados, é possível concluir que neosporose e leptospirose são doenças endêmicas em bovinos e se caracterizam como relevante problema de saúde pública e animal em Goiandira, GO, Brasil.

PALAVRAS-CHAVES: Aborto, bovinos, leptospirose, neosporose, prevalência.

\section{ABSTRACT}

\section{SEROPREVALENCE OF ANTIBODIES ANTI-Neospora caninum AND ANTI-Leptospira interrogans IN TWO PROPERTIES OF DAIRY COWS WITH REPORTS OF REPRODUCTIVE LOSSES IN GOIANDIRA, GOIÁS STATE, BRAZIL}

The aim of this study was to determine the seroprevalence of antibodies anti-Neospora caninum and anti-Leptospira interrogans in dairy cows from Goiandira, Goiás State, Brazil. Serum samples of 53 dairy cows from two herds were assayed for anti-N. caninum antibodies using an indirect immunofluorescent antibody test (IFAT) and microscopic-agglutination technique (MAT) for L. interrogans agglutinins. Sera reacting at dilutions $\geq 1: 50$ and $\geq 1: 100$ were considered positive for $N$. caninum and $L$. interrogans antibodies respectively. It was found that $35.9 \%$ (14 cows) of the samples from Farm 1 and $64.3 \%$ (9 cows) from Farm 2 were positive for
N. caninum. For L. interrogans, 87.2\% (34 cows) from Farm 1 and $64.3 \%$ (9 cows) from Farm 2 were positive. The serovars founded were: wolffi (21.74\%); hardjo (18.11\%); bratislava $(14.49 \%)$; australis (12.32\%); tarassovi (12.32\%); icterohaemorrhagiae (7.25\%); sentot (5.80\%), grippotyphosa (5.07\%); patoc $(2.17 \%)$; cynoptero $(0.72 \%)$. According to the results, it was possible to conclude that neosporosis and leptospirosis are endemic in dairy cows and may also be a significant animal and human health problem in Goiandira, GO, Brazil.

KEYWORDS: Abortion, bovine, leptospirosis, neosporosis, prevalence. 


\section{INTRODUÇÃO}

Neospora caninum e Leptospira interrogans são considerados importantes agentes infecciosos que afetam a reprodução de bovinos (COSTA et al., 2001; HOMEM et al., 2001), podendo resultar em aborto ou nascimento de bezerros fracos (BIELSA et al., 2004).

Neosporose bovina é causada por um parasito coccídeo, formador de cistos denominado Neospora caninum (DUBEY et al., 1998). O coiote e o cão são os hospedeiros definitivos, que eliminam oocistos após ingestão de tecido ou órgão de hospedeiros intermediários, com os cistos do agente, representados pelos bovinos (ALMEIDA, 2004).

A infecção por $N$. caninum não produz sinais clínicos em vacas, exceto pelos abortos encontrados. Animais de qualquer idade e a qualquer momento da gestação podem abortar, tanto gado de leite quanto gado de corte (PATITUCCI et al., 1999). Pesquisas realizadas no Brasil, pelo diagnóstico do agente por imunohistoquímica e reação em cadeia por polimerase (PCR), demonstraram tal fato. O diagnóstico para este coccídeo deve ser incluído em rotina como mais um dos possíveis causadores de aborto (GENNARI, 2004), já que neosporose é considerada a principal causa de perdas reprodutivas em países onde a brucelose foi controlada (PATITUCCI et al., 2000).

Outra doença que também causa abortos em vacas é a leptospirose, provocada por bactérias do gênero Leptospira. Esse gênero compreende as espécies L. interrogans e L. biflexa, que são divididas em vários sorovares. Os sorovares de L. biflexa são de vida livre, não patogênicos. Já os de $L$. interrogans abrangem todos os que infectam humanos e animais (SCHIMIDT et al., 2002).

Trata-se de uma zoonose e seu agente etiológico compreende mais de 180 sorovares (SCHIMIDT et al., 2002). Apresenta alta prevalência em países tropicais, o que é explicado pelas altas precipitações pluviométricas e solo neutro a alcalino (ALMEIDA, 1999). A presença e a sobrevivência do agente no ambiente são favorecidas, sobretudo, pela umidade e pH neutro (HOMEM et al., 2001).

Em bovinos a leptospirose provoca aborto, infertilidade, anorexia, pirexia, apatia, icterícia, anemia hemolítica, hemoglobinúria, mastite e até morte, na de- pendência do sorotipo envolvido e da idade do indivíduo acometido (HOMEM et al., 2001). Quando presente nos rebanhos, difunde-se rapidamente, alcançando altos índices de morbidade com casos mais graves em animais mais jovens (ALMEIDA, 1999). MINEIRO et al. (2007) constataram a associação entre infecção e ocorrência de transtornos reprodutivos, sendo Hardjo o sorovar que apresentou maior associação.

FAVERO et al. (2001), em levantamento sorológico para leptospirose em vários estados do Brasil, alcançaram as seguintes faixas percentuais de animais reativos a pelo menos uma variante sorológica: $\mathrm{SC}, \mathrm{CE}$, PR, DF, SP e PA (25,2 a 38,3\%); PB, TO, RJ, MG, GO, RO, RN, PI, MA e AL (40,7 a 58,4\%); BA, ES, MS e MT (superior a $61,0 \%$ ).

Mesmo não havendo dados científicos sobre a epidemiologia de doenças reprodutivas no município de Goiandira, GO, relatos de abortos e repetição de cio sugerem a ocorrência de doenças relacionadas com essas alterações. Dadas as altas prevalências de leptospirose em rebanhos bovinos e pelo fato de neosporose ser pouco conhecida na região, optou-se pelo levantamento da soroprevalência dessas doenças em duas propriedades com relatos de perdas reprodutivas no dado município.

\section{MATERIAL E MÉTODOS}

Localizado na região sudeste do estado de Goiás, o município de Goiandira possui aproximadamente 5.000 habitantes e apresenta a maioria de suas propriedades rurais de pequeno porte com baixo nível tecnológico. Distanciado $260 \mathrm{~km}$ da capital do seu estado, Goiânia, tem a agropecuária como sua atividade econômica principal. Este município é abrangido pelo clima tropical, apresentando vegetação típica de cerrado, com uma estação seca com temperaturas mais amenas e outra quente e chuvosa.

Para a escolha das fazendas foi utilizada a amostragem não probabilística por julgamento especializado, conforme GRESSLER (2004). Dentre os proprietários que se dispuseram a participar desta pesquisa, intencionalmente escolheram-se os rebanhos que apresentavam histórico recente de problemas reprodutivos. As fazendas se localizavam a $20 \mathrm{~km}$ de distância entre elas e eram pertencentes ao mesmo município. Utilizaram-se todos os bovinos 
de cada uma das duas propriedades neste estudo. Amostras de sangue de 53 bovinos foram colhidas de fêmeas, adultas, em fase de pré-parto, secas e em lactação, das raças Gir e Mestiças Gir/Holandês sem grau de sangue definido, pertencentes ao município de Goiandira, Goiás. Trinta e nove animais da Fazenda 1 e quatorze animais da Fazenda 2, que se encaixavam nas categorias descritas anteriormente, foram utilizados para colheita. Histórico de vacinação para $L$. interrogans e $N$. caninum era inexistente nas duas propriedades.

Colheram-se as amostras de sangue por meio de punção de veia jugular, sendo armazenadas em tubos de ensaio identificados e sem anticoagulante. O material coletado foi transportado sob refrigeração até o laboratório de Patologia Clínica do Hospital Veterinário da Universidade Federal de Uberlândia, onde se extraiu o soro sanguíneo de cada amostra, dividindo-as em duas frações. Foram feitas as devidas identificações e posterior armazenamento a uma temperatura de $-20^{\circ} \mathrm{C}$.

Enviou-se uma fração do material coletado para o Instituto de Patologia Tropical e Saúde Pública (IPTSP) da Universidade Federal de Goiás, onde foi efetuado o exame sorológico para $N$. caninum através da técnica de Reação de Imunofluorescência Indireta (RIFI), padronizando-se como positivos os títulos maiores ou iguais a 1:50, conforme SARTOR et al. (2003). A outra fração foi enviada para o Laboratório de Doenças Infectocontagiosas da Faculdade de Medicina Veterinária da Universidade Federal de Uberlândia, para a detecção de anticorpos anti- $L$. interrogans para onze sorovares (wolffi, hardjo, bratislava, australis, tarassovi, icterohaemorrhagiae, sentot, grippotyphosa, patoc, cynoptero e copenhage), pelo método de Soroaglutinação Microscópica (SAM), padronizando-se como positivos os títulos maiores ou iguais a $50 \%$ de aglutinação de antígenos por campo a uma diluição de 1:100 do soro sanguíneo, conforme BRASIL (1995).

Aplicou-se o teste de Qui-quadrado (SIEGEL, 1975) aos dados conjuntos com nível de significância de 0,05 em uma prova bilateral. O objetivo era verificar a existência ou não de diferenças estatisticamente significantes entre as frequências relativas à presença de $N$. caninum, L. interrogan e seus sorovares, encontradas nos animais das duas fazendas.

\section{RESULTADOS E DISCUSSÃO}

Na Fazenda 1, dos 39 animais examinados, quatorze $(35,9 \%)$ reagiram sorologicamente à Imunofluorescencia Indireta para $N$. caninum e em 34 $(35,9 \%)$ detectaram-se anticorpos anti-L. interrogans. $\mathrm{Na}$ Fazenda 2, das quatorze fêmeas examinadas, nove $(64,3 \%)$ reagiram sorologicamente à reação Imunofluorescencia Indireta para $N$. caninum, e o mesmo número de observações foi encontrado para sororreagentes à L. interrogans (64,3\%). Em uma análise global, dos 53 animais, encontrou-se a prevalência de $43,4 \%$ para neosporose e $81,1 \%$ para leptospirose (Tabela 1 ).

Dentre os 34 animais sororreagentes para $L$. interrogans na Fazenda 1, dez também eram positivos para neosporose. Em relação à Fazenda 2, dos nove que reagiram ao SAM, cinco também apresentaram anticorpos anti- $N$. caninum.

TABELA 1. Frequência de animais sororreagentes para L. interrogans e N. caninum nas fazendas 1 e 2, Goiandira, GO, 2007

\begin{tabular}{lccccc}
\hline \multirow{2}{*}{ Locais } & $\mathrm{N}$ & \multicolumn{2}{c}{ L. interrogans } & \multicolumn{2}{c}{ N. caninum } \\
\cline { 2 - 6 } & & $\mathrm{n}$ & $\%$ & $\mathrm{n}$ & $\%$ \\
\hline Fazenda $1^{*}$ & 39 & $34^{\mathrm{a}}$ & 87,2 & $14^{\mathrm{b}}$ & 35,9 \\
Fazenda 2 & 14 & 09 & 64,3 & 09 & 64.3 \\
Total & 53 & 43 & 81,1 & 23 & 43,4 \\
\hline
\end{tabular}

$*_{\mathrm{p}}<0,05$

Referindo-se especificamente a animais sororreagentes a $N$. caninum, pode-se observar uma superioridade da prevalência encontrada neste trabalho (43\%), se comparada à citada por GENNARI (2004), que identificou frequências de $8,7 \%$ no estado de Rondônia e 21,55\% no estado do Paraná. A presença de cães em convívio comum com os bovinos nas duas propriedades pode justificar esses altos índices de soropositividade para $N$. caninum (ROMANELLI et al., 2007).

A soroprevalência para $L$. interrogans também excedeu aos relatos encontrados na literatura, determinando-se uma média de $81,1 \%$ de sororreagentes a L. interrogans. FAVERO et al. (2001), em estudo no estado de Goiás, encontraram médias de 40,7\% a $58,4 \%$ de animais soropositivos. CAMPOS JUNIOR et al. (2006), também em levantamento sorológico em 
machos reprodutores no mencionado estado, obtiveram a prevalência de $78,28 \%$ de animais positivos.

Essas elevadas taxas podem ser relacionadas à presença de fatores que predispõem um ambiente contaminado (hospedeiro disseminador, contaminação do meio com Leptospiras vivas, sobrevivência destas no ambiente, contato com indivíduos susceptíveis) e as condições de manejo do rebanho (TOMICH et al., 2007).

Na Fazenda 1, a infecção por L. interrogans se mostrou maior que a infecção por $N$. caninum. Já na Fazenda 2 não houve diferenças estatisticamente significantes entre as doenças. Segundo resultados determinados pelos exames sorológicos executados em animais do município de Goiandira e por não haver diferenças significantes entre os resultados de sorologia de cada propriedade, é possível comprovar a disseminação dos agentes causadores tanto de leptospirose quanto de neosporose, na região estudada, com frequências altas.

Dada a aplicação do Programa Nacional de Erradicação de Brucelose e Tuberculose Animal, instituído em 2001 pelo Ministério da Agricultura, Pecuária e Abastecimento Brasileiro, pode-se considerar que brucelose é uma doença já controlada nos rebanhos estudados, não representando a principal causa de problemas reprodutivos neles encontrados. ESCAMILLA et al. (2007), buscando uma correlação entre os resultados sorológicos e os achados de necropsia de fetos abortados em um rebanho, sugerem que tais lesões foram provocadas em sua maioria por agentes bacterianos, mais especificamente Leptospira spp. e Brucella spp., seguidos do cocídeo N. caninum.

GROOMS (2006) afirmou que é necessário fazer um diagnóstico diferencial entre doenças que provocam perdas reprodutivas, para um melhor controle delas. No entanto, é importante salientar que foram encontrados animais reagentes para ambos os testes, demonstrandose, dessa forma, a ocorrência concomitante de duas doenças reprodutivas, o que provavelmente dificulta o diagnóstico e tratamento a campo.

$\mathrm{Na}$ Fazenda 1 encontraram-se, em quantidade decrescente de prevalência, os seguintes sorovares: wolffi, hardjo, bratislava, australis, tarassovi, icterohaemorrhagiae, sentot, grippotyphosa e patoc. $\mathrm{Na}$ Fazenda 2 foram encontrados: tarassovi, wolffi, bratislava, grippotyphosa e cynoptero, (Tabela 2). Numa análise global, obtiveram-se também em ordem decrescente: wolffi, hardjo, bratislava, australis, tarassovi, icterohaemorrhagiae, sentot, grippotyphosa, patoc e cynoptero (Tabela 3 ).

Sorovares comuns aos bovinos, como hardjo e wolffi, são de transmissão direta, ou seja, a transmissão ocorre de um indivíduo para o outro e está diretamente ligada às condições de manejo. Sorovares acidentais como tarassovi e sejroe infectam os bovinos que habitam um ambiente favorável ao desenvolvimento desses sorovares. Fatores que podem favorecer a manutenção desses agentes no meio são: condições climáticas favoráveis, como alta temperatura e umidade, e pH dos solos, de neutro a alcalino (TOMICH et al., 2007).

Foi estatisticamente maior, em um nível de significância de 0,05, a frequência dos sorovares tarassovi e wolffi na Fazenda 2. O sorovar bratislava não apresentou diferença estatisticamente significante entre as duas propriedades, e os demais tiveram frequências baixas ou não identificação pela sorologia, não sendo possível a comparação entre eles. Com isso, levantase a hipótese de que, nos rebanhos estudados, tanto fatores de ambiente quanto de manejo favoreceram o contato entre hospedeiro e os parasitos, resultando na identificação de anticorpos anti-Neospora e antiLeptospira.

TABELA 2. Frequência de sorovares de L. interrogans nas fazendas 1 e 2, Goiandira, GO, 2007

\begin{tabular}{lcccc}
\hline \multirow{2}{*}{ Sorovares } & \multicolumn{2}{c}{ Fazenda 1 Fazenda 2} \\
& $\mathrm{n}$ & $\%$ & $\mathrm{n}$ & $\%$ \\
\hline Australis & 17 & 13,7 & 00 & 00,0 \\
Bratislava* & $18^{\mathrm{a}}$ & 14,5 & $02^{\mathrm{b}}$ & 14,3 \\
Cynoptero & 00 & 00,0 & 01 & 07,1 \\
Copenhage & 00 & 00,0 & 00 & 00,0 \\
Grippotyphosa & 05 & 04,0 & 02 & 14,3 \\
Hardjo & 25 & 20,2 & 00 & 00,0 \\
Icterohaemorrhagiae & 10 & 08,1 & 00 & 00,0 \\
Patoc & 03 & 02,4 & 00 & 00,0 \\
Sentot & 08 & 06,4 & 00 & 00,0 \\
Tarassovi & 12 & 09,8 & 05 & 35,7 \\
Wolff* & $26^{\mathrm{a}}$ & 21,0 & $04^{\mathrm{b}}$ & 28,5 \\
Total & 124 & 100,0 & 14 & 100,0 \\
\hline
\end{tabular}

* Sorovares que apresentaram diferenças estatisticamente significantes entre si. $\mathrm{p}<0,05$ 
Segundo ALMEIDA (1999), os sorovares mais frequentemente encontrados na América são: pomona, hardjo, wolffi e grippotyphosa. O presente estudo identificou a importância de outros sorovares, além dos citados anteriormente. São eles: bratislava, tarassovi e australis. Wolffi e hardjo foram os mais encontrados numa análise global dos animais estudados. Grippotyphosa foi encontrado apenas na Fazenda 2 e o sorovar pomona não foi estudado.

Em análise prospectiva, visando a prevenção, aventa-se a necessidade de adotar a vacinação. Porém em todas as bacterinas encontradas no mercado estão presentes os sorovares hardjo, icterohaemorrhagiae e pomona. Duas delas apresentam o sorovar bratislava, sendo que dessas somente uma está associada a wolffi.

Uma vacina possui em sua composição o sorovar tarassovi, estando associado à bratislava, hardjo e pomona, porém não se encontra o sorovar wolffi em sua composição. Tais observações permitem considerar que as vacinas encontradas no mercado não abrangem todos os sorovares identificados por este estudo. Isso significa que, mesmo sendo feita vacinação nos rebanhos avaliados, eles não estariam devidamente protegidos e os prejuízos causados pela leptospirose provavelmente continuariam.

TABELA 3. Frequência de sorovares de $L$. interrogans mais encontrados nas fazendas 1 e 2, Goiandira, GO, 2007

\begin{tabular}{lcc}
\hline Sorovares & Frequência & $\%$ \\
\hline Wolffi & 30 & 21,74 \\
Hardjo & 25 & 18,11 \\
Bratislava & 20 & 14,49 \\
Australis & 17 & 12,32 \\
Tarassovi & 17 & 12,32 \\
Icterohaemorrhagiae & 10 & 07,25 \\
Sentot & 08 & 05,80 \\
Grippotyphosa & 07 & 05,07 \\
Patoc & 03 & 02,17 \\
Cynoptero & 01 & 00,72 \\
Copenhage & 00 & 00,00 \\
\hline Total & 138 & 100,00
\end{tabular}

Os resultados deste estudo demonstram a relevância de levantamentos de soroprevalências de anticorpos anti-L. interrogans nas diversas regiões do Brasil, buscando reconhecer os principais sorovares em cada rebanho. Isso se deve ao fato de que os anticorpos produzidos são específicos para a variedade sorológica que induziu a sua produção, ou seja, não há imunidade cruzada (FAINE et al., 1999). Descute-se ainda a possibilidade do uso de vacinas autógenas, aprovadas pelo MAPA (BRASIL, 2002), em propriedades onde se detecta a presença de sorovares não comuns à maioria das vacinas comerciais.

\section{CONCLUSÕES}

Após estudo sorológico em dois rebanhos bovinos leiteiros com relatos de perdas reprodutivas no município de Goiandira, Goiás, identificaram-se fêmeas reagentes para $L$. interrogans e $N$. caninum com frequências elevadas, $81,1 \%$ e $43,4 \%$ respectivamente, apresentando o sorovar wolffi como o de maior prevalência.

\section{AGRADECIMENTOS}

Aos funcionários do Laboratório de Doenças Infectocontagiosas e de Patologia Clínica da Universidade Federal de Uberlândia e ao Instituto de Patologia Tropical e Saúde Pública (IPTSP) da Universidade Federal de Goiás, pela colaboração nas análises laboratoriais.

\section{REFERÊNCIAS}

ALMEIDA, L. P. Epidemiologia da leptospirose: fontes de infecção e vias de transmissão. Cadernos Didáticos 61 UFV, Viçosa, 1999. $32 \mathrm{p}$.

ALMEIDA, M. A. O. Epidemiologia de Neospora caninum. Revista Brasileira de Parasitologia Veterinária, v. 13, p. 38-40, 2004.

BIELSA, J. M.; ROMERO, J. J.; HEUER, C. Controle de Neosporose em bovinos com Bovilis ${ }^{\circledR}$ Neoguard: a experiência de campo. Revista Brasileira de Parasitologia Veterinária, v. 13, p. 34-37, 2004.

BRASIL. Ministério da Agricultura, Pecuária e Abastecimento. Regulamento Técnico para a Produção, o Controle e o Emprego de Vacinas Autógenas de Uso Veterinário. 2002. Disponível em: <http://extranet.agricultura.gov.br/sislegis-consulta/servlet/ VisualizarAnexo?id=13438>. Acesso em: 26 mar. 2008. 
BRASIL. Ministério da Saúde. Fundação Nacional da Saúde. Manual de leptospirose. 2 ed. Brasília, 1995. 98 p.

CAMPOS JÚNIOR, A. C. P.; FRENEAU, G. E.; JULIANO, R. S.; ACYPRESTE, C. S.; DIAS FILHO, F. C.; MARTINS, M. E. Prevalência de anticorpos Antileptospira em machos bovinos na microrregião de Goiânia. Ciência Animal Brasileira, v. 7, n. 4, p. 439-446, out.-dez. 2006

COSTA, G. H. M.; CABRAL, D.D.; VARANDAS, N. P.; SOBRAL, E. A.; BORGES, F. A.; CASTAGNOLLI, K. C. Frequência de anticorpos anti-Neospora caninum e anti-Toxoplasma gondii em soros de bovinos pertencentes aos estados de São Paulo e Minas Gerais. Semina, v. 22, n. 1, p. 57-62, 2001.

DUBEY, J. P.; CARPENTER, J. L.; SPEER, C. A.; TOPPER, M. J.; UGGLA, A. Newly recognized fatal protozoan disease of dogs. Journal of the American Veterinary Medicine Association, v. 192, p. 1269-1285, 1998.

ESCAMILLA, P. H.; MARTINÉZ, J. J. M.; MEDINA, M. C.; MORALES, E. S. Frequency and causes of infectious abortion in dairy herd in Querataro, Mexico. Canadian Journal of Veterinary Research, v. 71, n. 4, p. 314-317, 2007.

FAINE, S.; ADLER, B.; BOLIN, C.; PEROLAT, P. Leptospira and leptospirosis. 2. ed. Melbourne: MediSci, 1999. 272 p.

FAVERO, M.; PINHEIRO, S. R.; VASCONCELLOS, S. A.; MORAIS, Z. M.; FERREIRA, F.; FERREIRA NETO, J. S. Leptospirose bovina: variantes sorológicas predominantes em colheitas efetuadas no período de 1984 a 1997 em rebanhos de 21 estados do Brasil. Arquivo do Instituto Biológico, v. 68, n. 2, p. 29-35, 2001.

GENNARI, S. M. Neospora caninum no Brasil: situação atual da pesquisa. Revista Brasileira de Parasitologia Veterinária, v. 13, p. 23-28, 2004.

GROOMS, D. Reproductive losses caused by bovine viral diarrhea virus and Leptospirosis. Theriogenology, v. 6, n. 3, p. 624-628, 2006.

HOMEM, V. S. F.; HEINEMANN, M. B.; MORAIS, Z. M.; VASCONCELLOS, S. A.; FERREIRA, F.; FERREIRA NETO, J. S. Estudo epidemiológico da leptospirose bovina e humana na
Amazônia oriental brasileira. Revista da Sociedade Brasileira de Medicina Tropical, v. 34, n. 2, p. 173-180, 2001.

MINEIRO, A. L. B. B.; BEZERRA, E. E. A.; VASCONCELLOS, S. A.; COSTA, F. A. L; MACEDO, N. A. Infecção por leptospira em bovinos e sua associação com transtornos reprodutivos e condições climáticas. Arquivo Brasileiro de Medicina Veterinária e Zootecnia, v. 59, n. 5, p. 1103-1109, 2007.

PATITUCCI, A. N.; PEREZ, M. J.; ISRAEL, K. S.; ROZAS, M. A. Prevalencia de anticuerpos séricos contra Neospora caninum en dos rebaños lecheros de la IX Región de Chile. Archivo de Medicina Veterinária, v. 32, n. 2, p. 209-214, 2000.

PATITUCCI, A. N.; PEREZ, M. J.; LUDERS, C. F.; RATTO, M. H.; DUMONT, A. G. Evidencia serológica de infección por Neospora caninum en rebaños lecheros del Sur de Chile. Archivo Medicina Veterinária, v. 31, n. 2, p. 215-218, 1999.

ROMANELLI, P. R.; FREIRE, R. L.; VIDOTTO, O.; MARANA, E. R. M.; OGAWA, L.; DE PAULA, V. S. O.; GARCIA, J. L.; NAVARRO, I. T. Prevalence of Neospora caninum and Toxoplasma gondii in sheep and dogs from Guarapuava farms, Parana, State, Brazil. Research in Veterinary Science, v. 82, p. 202-207, 2007.

SARTOR, I. F.; HASEGAWA, M. Y.; CANAVESSI, A. M. O.; PINCKNEY, R. D. Ocorrência de anticorpos de Neospora caninum em vacas leiteiras avaliados pelos métodos de ELISA e RIFI no município de Avaré, SP. Semina Ciências Agrárias, v. 24, n. 1, p. $3-10,2003$.

SCHMIDT, V.; AROSI, A.; SANTOS, A. R. Levantamento sorológico da leptospirose em caprinos leiteiros no Rio Grande do Sul, Brasil. Ciência Rural, v. 32, n. 4, p. 609-612, 2002.

SIEGEL, S. Estatística não-paramétrica, para as ciências do comportamento. Trad. Alfredo Alves de Farias. São Paulo: Ed. McGraw-Hill do Brasil, 1975. 350 p.

TOMICH, R. G. P.; BOMFIM, M. R. Q.; KOURY, M. C.; PELLEGRIN, A. O.; PELLEGRIN, L. A.; KO, A. I.; BARBOSASTANCIOLIL, E. F. Leptospirosis Serosurvey in bovines from Brazilian Pantanal using igG Elisa with recombinant protein LipL32 and microscopic agglutination test. Brazilian Journal of Microbiology, v. 38, p. 674-680, 2007. 